\title{
ANSI laser standards, education (Z136.5), research, development or testing (Z136.8)
}

K. Barat

K. Barat, "ANSI laser standards, education (Z136.5), research, development or testing (Z136.8)," Proc. SPIE 9289, 12th Education and Training in Optics and Photonics Conference, 928926 (17 July 2014); doi: 10.1117/12.2070723

Event: 12th Education and Training in Optics and Photonics Conference, 2013, Porto, Portugal 


\title{
ANSI Laser Standards, Education (Z136.5), Research, Development or Testing (Z136.8) \\ K. Barat ${ }^{\mathrm{a}}$ \\ ${ }^{a}$ Laser Safety Solutions, 42179 W. Santa Fe St, Maricopa, Arizona, USA 85138
}

\begin{abstract}
Several factors affect laser use in educational settings. First is the lower cost of lasers, in particular, diode have made lasers more accessible for laser classroom use (think of the hand held laser in red, green and blue). Second in the research and development, no technology has made the impact of the laser. Third the importance of introducing students to this technology. To the point no discipline is laser free. To address laser safety in the academic setting two American National Standard Institute Standards have been developed. The most recent Z136.8 Safe Use of Lasers in Research, Development and Testing Setting, published in 2012, Z136.5 Laser Safety in Education -2009 version was published.

Z136.5 provides guidance for educators starting in public school and ranging into the college level. This includes classroom demonstrations and science fair demonstrations. Z136.8 is geared for the Graduate and Commercial research level. Z136.5 relies on the use of pre-approved safety lessons plans and appreciation of student maturity or lack of, Z136.8 relies heavily on cooperation between the user and the laser safety officer. The presentation will cover the contents of each and the different approaches taken.
\end{abstract}

Keywords: Laser Safety, Laser Safety Officer ANSI, Z136.5, Z136.8

\section{INTRODUCTION}

Every aspect of modern society has been touched by the invention of the laser. This ranges from medical application thought impossible a decade ago to products in the hands of the consumer. Therefore, to provide the modern workforce an understanding of lasers and how to work with them is critical. A number of institutions are addressing this need.

Many schools from the high school level and lower are introducing students to lasers and optics. This continues up into the undergraduate level, as well as schools dedicated solely to optics and photonics. At the graduate level, many research projects involve the use of laser technology as a tool to help projects developing new types of laser systems such as the optical accelerator. The efforts of these classes and schools is training students to work with optics and lasers but attention to laser safety is most often lacking.

This is not to say they avoid instructing students on laser safety or are willing to have laser injuries. Class time is limited and for laser safety it is expected that the will pass on good practices and encourage laser safety. It is the experience of this author that this type of approach is extremely inconsistent and lacking. This includes laser safety training at the graduate school and higher level. The only exception to this is graduate and Post Doc students working at US national laboratories, such as Lawrence Berkeley National Laboratory.

Sometimes the reasons why laser safety is not given the attention it deserves is a combination of reasons. This includes instructors having a lack of guidance to fall back on, the perception that laser safety hinders the work/learning experience, or the misconception that if students memorize a set of laser safety rules, that means they will apply them. The rules are good practices, such as: Do not look directly at the laser,

\footnotetext{
12th Education and Training in Optics and Photonics Conference, edited by

Manuel F. P. C. Martins Costa, Mourad Zghal, Proc. of SPIE Vol. 9289, 928926

(C) 2014 SPIE, OSA, IEEE, ICO · doi: 10.1117/12.2070723
}

Proc. of SPIE Vol. 9289 928926-1 
use the lowest possible power, block stray beams and beams should not be at eye level while sitting or standing, etc. Laser safety requires active action, application and understanding; it is not the same as memorizing a multiplication table. To that end the American National Standards Institute (ANSI) Z136 Committee, which deals with laser safety, has developed and published two laser user standards to deal with this issue. ANSI Z136.5 Safe Use of Lasers in Educational Environments, provides laser safety guidance from the elementary to undergraduate level. Z136.8 Safe Use of Lasers in Research, Development or Testing covers the University research level. This paper will provide some background as well as a review of each.

As costs have dropped, more and more laser sources and wavelengths are within reach of teaching institutions and even students. This includes handheld lasers in the red, green and blue wavelengths. On the positive side, the majority of lasers used in educational settings are commercial products. Hence they are manufactured with a number of product safety features built in. This includes emission indicators, aperture labels, remote interlock connectors and protective housings to name a few. A source of laser products that many institutions over look is the local hardware store (alignment levers, can be found that are made to be stable for reasonable prices). Unfortunately, the reality is none of these product safety controls prevent misuse of the laser product. In this manuscript I will use the term laser radiation rather than the term laser light. Why is that? The term radiation tends to get a greater response than the soft tone word light. The word, light, makes us feel comfortable but tends to decreasing the attention to safety.

\subsection{Z136.5 Safe Use of Lasers in Educational Settings}

This standard was first published in 2000 and updated in 2009. The scope of the standard is described in section 1.1 which reads: This standard addresses laser safety concerns and situations characteristic of the education environment. This standard is not a substitute for ANSI Z136.1-2007, which is required for a full understanding of laser safety officer duties and laser hazard evaluation. Environments characteristic of educational institutions wherein lasers may be found include teaching laboratories, classrooms, lecture halls, science fairs, museums, and student projects on and off campus. This standard is intended for faculty and students using lasers at primary, secondary, and college levels of education excluding graduate level research laboratories. The wavelength range of interest includes the ultraviolet, visible, and infrared regions of the electromagnetic spectrum, specifically the wavelength from 0.18 micrometer to 1 millimeter.

As in all the laser safety standards for Class 3B and Class 4 laser use, the standard calls for the designation of a Laser Safety Officer (LSO). This person is to administer and manage the laser use at the facility. They need to be knowledgeable of laser hazards and controls. For laser or laser systems with lower class lasers (lower output) an LSO is not required (this not completely true). Institutions need to be aware that some equipment that is completely safe during normal operation may contain a Class $3 \mathrm{~B}$ or Class 4 laser and access to this level of laser radiation may be present during service or maintenance. In the educational arena, such devices are usually found at the college level or laser technician training schools.

Laser hazards fall into three groups: real injuries, perception of injury and potential injuries. Real injuries are a rather simple concept. One has received sufficient energy to cause biological damage. Depending on the wavelength and irradiance (note not just power of the beam), the effect of the exposure may be 
immediate (400-1400nm) to delayed (180-400nm, .1400 to $1 \mathrm{~mm})$. Institutions need to have a plan in place, for example, as most schools do for items above first aid to, address a possible laser eye injury. In the case of eye injuries, knowing an eye clinic or retinologist is an example of good planning.

Perception of injury involves could be exposure to a low power beam or one seeing laser beams reflected on an optic, giving the impression one has been exposed to laser radiation (light). Experimental laser set ups should be designed to contain this type of issue. Beams should be contained to inside the classroom or demonstration enclosure or device.

Potential injuries, is the role of safety planning, taking steps to mitigate a potentially hazardous situation. Following is a key element of this standard that is complementary to standard teaching practices. The standard calls for review of all lesson plans that involve laser use. The guidance can be found in section 4.1.1 Standard Operating Procedures (SOPs), Laser Lesson Plans and Controls. This can be performed by the LSO or delegated to a faculty member or outside resource. Once the lesson plan with controls has been approved, the process does not have to be repeated as long as the plan is followed each time.

Section 4.2 Controls by Grade Level, breaks down guidance to the following groups: Grades K-6, Grades 7-8, Grades 9-12, Vocational School, College and University Students, Classroom Demonstrations and Lecture Halls. While section 4.3covers multi-use laser settings.

Section 5 covers "Laser Safety Programs and Student Training". The subsections have the titles, 5.1 General, 5.2 Educational Laser Safety Committee, 5.3 Student Laser Safety Training, 5.4 Faculty and Staff Laser Safety Training.

The standard recognizes the fact that many primary and secondary schools will not have a designated LSO, and still might have class projects that involve lasers. Therefore, it recommends having a teacher who has had some laser safety training; this does not have to be at the same level of an LSO. It reminds faculty and staff of the responsibility they have when they introduce students to an environment that contains laser radiation. At each grade level the maturity of students needs to be considered as one decides on the level of controls that need to be put in place and yet still get the class lesson across.

\subsection{Z136.8 Safe Use of Lasers in Research, Development or Testing}

This standard, after a 5 year development effort, was first published in late 2012. The next edition is aiming for 2016-17. The standard addresses a number of items not found in Z136.1-2007 Safe Use of Laser or the other Z136 laser safety series standards.

The standards scope is rather simple, and really just repeats the title. It is in section 1.2 Application where its philosophy is made clear. "The objective of this standard is to provide reasonable and adequate guidance for the safe use of lasers and laser systems in research, development, and testing environment, where safety controls common for commercial laser may be either missing (nonexistent) or disabled."

At this level of educational facilities, laser safety falls most commonly, not to the instructor or senior scientist, but to the laser safety officer. The day to day laser safety is under the supervision of a Post Doc or senior graduate student. The safety culture of such a group is established by either the expectations of the institution or lead scientist. At this level, the laser safety officer needs all the assistance and tools they can acquire to monitor and set the safety tone. Here is where Z136.8 can be extremely helpful. 
First, it recognizes that institutional laser safety training is only an awareness step and that real laser safety comes from mentorship, also known as on the job training (OJT). It provides guidance on the topic, emphasizing that there is no set time period to accomplish OJT as well as the importance of documenting such activities. Second, that lasers used in research are not always commercial products and the exclusion of some commercial laser safety controls are acceptable by authorized and trained users as compared to general laser operators and the public.

Some of the topics the standard covers for the first time are, On the Job Training, User Facilities, Export Control, Beam path evaluation, Process interaction, Using laser use locations to vary control measures, use of Alignment eyewear and its selection, safety qualification of service personnel and noncommunication fiber optics, among other topics.

Z136.8 provides needed guidance to the laser safety officer, who is responsible for laser safety in the University setting. In addition, it helps explain to an institutions management the real world of laser use and safety at this level and how laser safety will interact with students.

\subsection{Definitions that will help the reading of this paper:}

Class 3B laser: Lasers may produce visible or invisible emissions. The Continuous Wave output power ranges from $5 \mathrm{~mW}$ to $500 \mathrm{~mW}$ atts. Class $3 \mathrm{~B}$ lasers may cause injury from direct and specular exposure.

Class 4 Laser: This laser can be visible or invisible emitting radiation greater than the $3 \mathrm{~B}$ range, with the capability of causing eye or skin injury from direct, specular or diffuse exposure.

Classroom environment: A classroom or closed room in which most, if not all, students are seated and one or more instructors are present to provide supervision.

Irradiance: Radiant power incident per unit area upon a surface, expressed in watts-per-centimeter squared.

Laser Safety Officer (LSO): One who has authority and responsibility to monitor and enforce the controls of laser hazards and effect the knowledgeable evaluation and control of laser hazards. This individual has the training and experience to administer a laser safety program.

Standard Operating Procedure: Formal written description of the safety and administrative procedures to be followed in performing a specific task.

\section{SUMMARY}

Lasers are an integral part of society and educational programs at all levels are finding more ways to introduce optics and photonics into the classroom. Even up to the college level, laser safety falls to individuals with limited experience in laser safety controls. To help provide some guidance to these individuals, two laser user standards have been developed Z136.5 and Z136.8. Each provides guidance for different school levels.

\section{REFERENCES}

[1] American National Standard for Safe Use of Lasers in Educational Insitution,-2009 Laser Institute of America., 13501 Ingenuity Drive, Suite 208 Orlando, FL 32826

[2] American National Standard for Safe Use of Lasers in Research, Development \& Testing, 2012 Laser Institute of America., 13501 Ingenuity Drive, Suite 208 Orlando, FL 32826

[3] Barat.K, "Laser Safety in the Lab" (2012) SPIE Press P.O. Box 10 Bellingham, WA 98227-0010. 